\section{Rescue of a lethal $T / t$ locus genotype by chimaerism with normal embryos}

THE mutation $T^{\mathrm{Hp}}$ at the $T / t$ locus in the mouse is unique among mammalian genes because it has a sharply defined maternal effect. Like other known $T / t$ locus dominant mutations, $T^{\mathrm{Hp}}$ yields a short-tailed phenotype in heterozygotes of both sexes. However, $T^{\mathrm{Hp}} /+$ females when mated with wild type fail to give birth to short-tailed progeny; examination of embryos shows that heterozygous embryos die late in gestation with seemingly minor defects such as spina bifida and polydactyly ${ }^{1-3}$. The precise reason for death has not been determined, but must depend on some defect intrinsic to the egg, because $T^{\mathrm{H} p} /+$ females successfully carry to term heterozygous embryos whose $T^{\mathrm{Hp}}$ gene is paternally derived. I report here that lethal $T^{\mathrm{Hp}} /+$ maternal heterozygotes are readily rescued if they are aggregated with normal embryos, but that the germ cell defect persists, because the chimaeras fail, if female, to transmit $T^{\mathrm{Hp}}$ to viable offspring.

Female $T^{\mathrm{Hp}} /+$ heterozygotes from our own stock that were black-and-tan and known to be homozygous $C C$ were crossed, after superovulation, to a random-bred Swiss albino stock (ICR) obtained commercially (Camm Research). Embryos recovered from these females $2 \mathrm{~d}$ after mating were approximately $8-16$ cells, and were aggregated in pairs with comparable embryos from ICR $\times$ ICR matings according to described procedures ${ }^{*}$ modified in accordance with practical instruction in chimaera formation kindly provided by V. E. Papaioannou. After $24 \mathrm{~h}$ of growth in vitro, well aggregated morulae and/or blastocysts were transplanted to pseudopregnant ICR hosts. Nineteen living young were obtained; their descriptions and breeding records are given in Table 1.

Sixteen animals were coat-coloured chimaeras. Six of these were phenotypically short-tailed, thus demonstrating simultaneously that $T^{\mathrm{HD}}$ is expressed in chimaeras, and that embryos obtaining $T^{\mathrm{H} p}$ from their mother can be rescued by chimaerism with wild-type embryos. The degree of expression is reduced, however; only two of the six obvious short-tailed animals had tails scored as 2/3-3/4 normal length, which is in the range for ordinary $T^{\mathrm{Hp}} /+$ animals. The others had only minor shortening or blunting of the tail tip; one male scored as normal tailed transmitted $T^{\mathrm{Hp}}$ to progeny and so was clearly a $T^{\mathbf{H p}} /+\longleftrightarrow+1+$ chimaera. $T^{\mathrm{Ho}} /-+$ embryos seem not to be compromised in their ability to participate in the formation of chimaeras, because of the 16 coat-colour chimaeras obtained, seven (very close to the

Table 1 Phenotypic expression and breeding behaviour of 19 mice derived from morulae from $q T^{\mathrm{Hp}} /+\times \delta$ ICR parents aggregated with morulae from $\&$ ICR $\times$ of ICR matings

\begin{tabular}{|c|c|c|c|c|c|c|}
\hline \multirow{3}{*}{ Sex } & \multirow{3}{*}{$\begin{array}{c}\text { Coat } \\
\text { colour } \\
(\% \text { albino })\end{array}$} & \multirow{3}{*}{$\begin{array}{l}\text { Tail } \\
\text { pheno- } \\
\text { type }\end{array}$} & \multicolumn{4}{|c|}{ Offspring $\times$ ICR } \\
\hline & & & No & rmal tail & & ort tail \\
\hline & & & Albino & Pigmented & Albino & Pigmented \\
\hline q & 100 & Normal & 25 & 一 & 一 & - \\
\hline † & 100 & Normal & 14 & - & - & - \\
\hline 움 & 100 & Normal & 10 & - & - & - \\
\hline$q$ & 50 & Normal & 6 & 1 & - & - \\
\hline 움 & 5 & Normal & 5 & 24 & 一 & - \\
\hline$\dot{q}$ & 50 & $2 / 3$ & 11 & 17 & - & - \\
\hline$q$ & 50 & $9 / 10$ & 38 & 28 & $\cdots$ & - \\
\hline q & 50 & $9 / 10$ & 36 & 38 & - & 一 \\
\hline o & 98 & Normal & 27 & - & - & - \\
\hline o & 95 & Normal & 53 & - & - & - \\
\hline$\sigma$ & 50 & Normal & 37 & 23 & - & $\ldots$ \\
\hline$\sigma$ & 50 & Normal & 45 & 24 & 一 & - \\
\hline 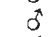 & 50 & Normal & 36 & - & - & - \\
\hline o & 60 & Normal & 32 & - & - & - \\
\hline 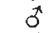 & 50 & Normal & 31 & 22 & - & - \\
\hline $0^{*}$ & 50 & Normal & 17 & 15 & 17 & 15 \\
\hline 0 & 75 & Blunt & 50 & 5 & 2 & 4 \\
\hline$\sigma^{*}$ & 10 & $9 / 10$ & 26 & 26 & 26 & 16 \\
\hline 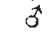 & 40 & $3 / 4$ & 16 & 14 & 16 & 14 \\
\hline
\end{tabular}

$1 / 2$ expected) contained the $T^{\mathrm{Hp}} /+$ genotype. Likewise, the degree of coat colour chimaerism was not noticeably different in normal compared to short-tailed animals, thus indicating that $T^{\mathrm{Hp}} /+$ cells are as competent as normal cells to contribute to that somatic tissue.

All three short-tailed males (and the one phenotypic normal mentioned above) produced substantial numbers of shorttailed progeny. None of the three female chimaeras, however, produced any offspring carrying $T^{\mathbf{H} \mathbf{p}}$, although all produced large numbers of pigmented progeny that demonstrated the production of oocytes derived from the $T^{\mathrm{H} p} /+$ component. Because the $T^{\mathrm{Hp}} /+$ component in these chimaeras is $\mathrm{C} / \mathrm{c}$, only inferences can be made about whether oocytes are also being produced by the ICR component. Because of the nature of sex differentiation in chimaeras, most phenotypic females are genotypically $q \longleftrightarrow q$ (ref. 5), so the most likely situation is that the ovaries of these animals contain both $T^{\mathrm{Hp}} /+$ and $+1+$ oocytes. Thus, it seems that neither somatic chimaerism nor like-sex gonadal chimaerism is able to restore normality to eggs that receive the $T^{\mathrm{Hp}}$ gene from the mother.

This work was supported by NIH grants HDO10668-02 and CA08748 and NSF grant PCM 77-17835. I thank C. Calo for assistance.

Sloan-Kettering Institute for Cancer Research,

DOROTHEa BenNetT

New York, New York 10021

Received 19 December 1977; accepted 8 February 1978

1. Johnson, D. R. Genetics 76, 795-805 (1974).
2. Johnson, D. R. Genet. Res. Camb, 24, 207-213 (1975).

3. Bennett, D. Cell 6, $441-454$ (1975)

4. Mintz, B. J. exp. Zool. 157, 273-292 (1964).

5. McLaren, A. Mammalian Chimaeras (Cambridge University Press, London, 1976).

\section{A stereometric pattern of distribution of acetylthiocholinesterase in the deep layers of the superior colliculus}

THE superior colliculus, although a layered structure, is not classified as a cortex because most of its neurones lack long apical dendrites. The colliculus, nevertheless, seems to share with the neocortex some of the features of columnar organisation. In particular, a periodic segmentation of certain afferent connections has been found, in which incoming fibres are arranged in the colliculus in bands or slabs, much like the ocular dominance columns in the striate cortex ${ }^{1-6}$. The possibility that such a distribution pattern might be evident also in a histochemical analysis of the superior colliculus was raised by Ramon-Moliner's finding ${ }^{7}$, in a survey of acetylthiocholinesterase activity in the cat's brain stem, that this enzyme is distributed in a series of regularly spaced clumps in the deep collicular layers. Evidence is presented here that such enzyme-positive clumps are also seen in the monkey and that, in the cat at least, these clumps do indeed form longitudinal bands.

Observations were made in two Rhesus monkeys, five cats and one kitten aged 3 weeks. With one exception (adult cat), brains were fixed by mixed-aldehyde perfusion. Sections cut at $30-50 \mu \mathrm{m}$ on a freezing microtome were treated according to the protocols either of Karnovsky and Roots $^{8}$ or of Geneser-Jensen and Blackstadt ${ }^{9}$, usually with the addition of an inhibitor of nonspecific cholinesterases (ethopropazine). Control sections from one cat were incubated: in the absence of the acetylthiocholine iodide substrate; with butyrylthiocholine iodide; by the addition of eserine to the normal incubation medium $\left(10^{-3}-10^{-5} \mathrm{M}\right)$. One brain was perfused with saline only and blocked in the mid-sagittal plane. Half of the brain stem was processed immediately, without fixation; the other half was soaked in fixative for $2 \mathrm{~d}$ before being cut and stained. 